\title{
Metabolic Conversion of 1- and 2-Nitronaphthalene to 1- and 2-Naphthylamine in the Rat ${ }^{1,2}$
}

\author{
Dale E. Johnson ${ }^{3}$ and Herbert H. Cornish \\ Interdepartmental Program in Toxicology and the Department of Environmental and Industrial Health, \\ School of Public Health. The University of Michigan, Ann Arbor, Michigan 48109
}

Received August 23, 1977; accepted April 14, 1978

\begin{abstract}
Metabolic Conversion of 1- and 2-Nitronaphthalene to 1- and 2-Naphthylamine in the Rat. Johnson, D. E., AND CoRnish, H. H. (1978). Toxicol. Appl. Pharmacol. 46, 549-553. 1- and 2-Naphthylamine ( $\alpha$ - and $\beta$-naphthylamine) were isolated as urinary metabolites of 1- and 2nitronaphthalene, respectively, in the rat. Isolation and identification were accomplished using preparative thin-layer chromatography and gas-liquid chromatography/mass spectral analysis. The evidence that metabolism of nitronaphthalenes leads to formation of the corresponding amines, one of which ( $\beta$-naphthylamine) is a known carcinogen, suggests that human exposure to this nitro compound should be minimal. It also points out the important role of metabolic studies in the evaluation of potential chemical toxicity and suggests a critical reevaluation of compounds whose metabolism by known pathways could lead to the in vivo formation of carcinogenic compounds.
\end{abstract}

Carcinogenic aromatic amines and nitro compounds are metabolized to "activated" intermediates generally believed to be responsible for producing tissue alterations (Miller and Miller, 1969; Endo et al., 1971). $N$-Oxidation of 1- and 2-naphthylamine and nitroreduction of 1 - and 2-nitronaphthalene may lead to identical $N$-oxy intermediates (Fig. 1), which have been shown to be carcinogenic and/or mutagenic in several in vitro and in vivo studies (Bonser et al., 1963; Boyland et al., 1963; Perez and Radomski, 1965; Bell et al., 1968; Radomski et al., 1971; Ong and deSerres, 1972; Radomski et al., 1973).

In this report we give details on the isolation and identification of 1- and 2naphthylamine isolated from the urine of rats injected with the corresponding nitronaphthalene (Johnson and Cornish, 1976). This gives new evidence that the common intermediate hypothesis, shown in Fig. 1, is real, and thus the potential carcinogenicity of 2-nitronaphthalene must now be considered.

As shown in Fig. 1 considerable interest centered on studies of the metabolism of 1and 2-naphthylamine because of the demonstrated carcinogenicity of 2-naphthylamine. Since nitroreduction of the nitronaphthalenes may lead to the same intermediates as the

\footnotetext{
${ }^{1}$ This research was supported in part by NCI Grant 1 R01 CA 15082-02.

${ }^{2}$ A preliminary report of a portion of this work was presented at the 15 th Annual Society of Toxicology Meeting, Atlanta, Ga., March 1976.

${ }^{3}$ Sydnor Barksdale Penick Memorial Fellow, American Foundation for Pharmaceutical Education, during the course of this investigation. Present address: Hoechst-Roussel Pharmaceuticals, Inc., Somerville, N.J. 08876.
} 
$N$-oxidation of the naphthylamines, it was of interest to determine initially if this overall pathway was functional in the whole animal. Poirer and Weisburger (1974) had demonstrated, in vitro, that the reduction of aromatic nitro compounds to the corresponding amines could indeed occur. Thus, the purpose of the present study was to determine whether conversion of nitronaphthalenes to naphthylamines occurred in the rat. This, of itself, would not establish that common intermediates existed in the metabolism of these two series of compounds but would suggest the need for reexamination of the metabolic fate of the nitronaphthalenes, as well as renewed study of other compounds whose metabolites could give rise to carcinogenic compounds.

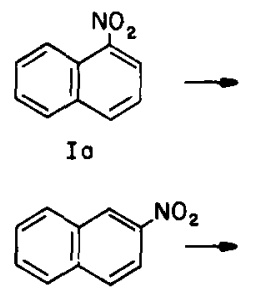

Ib<smiles>C#CC=Cc1cccc2cc([N+](=O)[O-])ccc12</smiles>

IIb<smiles>Oc1cccc2ccccc12</smiles>

III 0<smiles>CC(C)CCCO</smiles>

III 0<smiles>Nc1cccc2ccccc12</smiles><smiles>Nc1ccc2ccccc2c1</smiles>

IV $\mathrm{b}$

FIG. 1. Proposed common intermediates in the metabolism of the nitronaphthalenes and naphthylamines. Ia, 1-nitronaphthalene; IIa, 1-nitrosonaphthalene; IIIa, $N$-hydroxy-1-naphthylamine; IVa, 1-naphthylamine; Ib, 2-nitronaphthalene; IIb, 2-nitrosonaphthalene; IIIb, N-hydroxy-2-naphthylamine; IVb, 2-naphthylamine.

\begin{tabular}{|c|c|}
\hline Pathways known to exist & Reference \\
\hline \multicolumn{2}{|l|}{ In vivo } \\
\hline IVa $\rightarrow(\text { IIIa })^{a}+$ IIa & Radomski and Brill (1970) \\
\hline $\mathrm{IVb} \rightarrow(\mathrm{IIIb})^{b}+\mathrm{IIb}$ & Radomski and Brill (1970) \\
\hline $\mathrm{Ib} \rightarrow \mathrm{II} \mathrm{b}+(\mathrm{III} \mathrm{b})^{b}$ & Radomski et al. (1973) \\
\hline \multicolumn{2}{|l|}{ In vitro } \\
\hline $\mathrm{IVa} \rightarrow(\mathrm{III} a)^{b}+\mathrm{IIa}$ & Brill and Radomski (1971) \\
\hline $\mathrm{IVb} \rightarrow(\mathrm{IIIb})^{b}+\mathrm{IIb}$ & Brill and Radomski (1971) \\
\hline $\mathrm{Ia} \rightarrow \mathrm{IVa}$ & Poirier and Weisburger (1974) \\
\hline $\mathrm{Ib} \rightarrow \mathrm{IVb}$ & Poirier and Weisburger (1974) \\
\hline $\mathrm{Ia} \rightarrow \mathrm{IIIa}$ & Sternson (1975) \\
\hline
\end{tabular}

${ }^{a}$ Measured after conversion to IIa.

${ }^{b}$ Measured after conversion to IIb.

\section{METHODS}

1- and 2-Nitronaphthalene (1-NN, 2-NN) were purchased from Aldrich Chemical Company, Inc., recrystallized prior to use, and shown to be amine free on the basis of thin-layer chromatography (tlc) and gas-liquid chromatography (glc). 1Naphthylamine (1-NA) and 2-naphthylamine (2-NA) standards were purchased from Aldrich Chemical Company, Inc. and Sigma Chemical Company, respectively. 1-NN, 2-NN, and 1-NA were checked for purity and shown to be single components on the basis of melting points and tlc in five different solvent systems. In additon, 1-NA and 2 NA were analyzed by a combination of glc and mass spectrometry and found to be 
pure by these criteria. Solutions for injection were made in peanut oil with a small amount of ether for solubilization; dosages were $100 \mathrm{mg} / \mathrm{kg}$ body wt.

Single intraperitoneal injections of 1- or 2-nitronaphthalene were given to adult male Sprague-Dawley rats and subsequent $24 \mathrm{hr}$ urine samples collected on a freezing unit. The urine samples were thawed, pooled, diluted fourfold with distilled water, and extracted three times with ether. The ether layers and interfacial emulsion were removed, placed in glass-stoppered centrifuge tubes, frozen in an acetone-dry ice mixture, and centrifuged immediately upon thawing. The ether layer was removed, dried over anhydrous sodium sulfate, filtered, and concentrated under a stream of nitrogen. The residue was taken up in anhydrous methanol and applied to activated preparative tlc plates. ${ }^{4}$

The plates were developed in benzene: $95 \%$ ethanol (19:1) for $45 \mathrm{~min}$ and dried, and the 1- or 2-naphthylamine band (uv absorbing) was removed and eluted with ethyl acetate in a micro-descending chromatography column. The extracts were concentrated under nitrogen and the residues taken up in a small amount of methanol for $\mathrm{glc} / \mathrm{mass}$ spectral analysis. The glc/mass spectral analyses were performed on a AEI MS 30 interfaced to a PYE Model $104 \mathrm{glc}$ unit and a digital pdp $8 / \mathrm{m}$ data output system incorporating a Tektronix 4010-1 visual display unit. ${ }^{5}$ A 5 -ft column of $3 \% \mathrm{OV}-17$ on gas chrom $\mathrm{Q}$ was used for the GLC separation. (Conditions: glc, $180^{\circ} \mathrm{C}$ isothermal; MS, $25 \mathrm{eV}, 50 \mathrm{mV}$.)

\section{RESULTS}

The glc retention times and mass fragmentation spectra of 2-naphthylamine isolated as a metabolite of 2-nitronaphthalene and the 2-naphthylamine standard were identical. The base peak was the molecular ion $(m / e ~ 143)$ and the major fragmentation was a loss of $\mathrm{HCN},(\stackrel{+}{\mathrm{M}}-27)$ or $(\stackrel{+}{\mathrm{M}}-1-27)$, which is analogous to other aromatic amines and identical to published 2-naphthylamine spectra (Registry of Mass Spectral Data, 1974). The glc retention times and mass spectral data for 1-naphthylamine isolated as a metabolite of 1-nitronaphthalene and the 1-naphthylamine standard were also identical. The base peak was the molecular ion $(\mathrm{m} / \mathrm{e} / \mathrm{143})$, and the loss of $\mathrm{HCN}$ from 1naphthylamine also resulted in the $(\stackrel{+}{\mathrm{M}}-27)$ and $(\stackrel{+}{\mathrm{M}}-1-27)$ fragments.

\section{DISCUSSION}

The present study has demonstrated that 1- and 2-nitronaphthalene are converted to 1- and 2-naphthylamine, respectively, in the rat (Johnson and Cornish, 1976). This supports the in vitro work of Poirer and Weisburger (1974). Although no evidence has been presented in this paper on the nature of possible intermediates in the pathway from the nitro compound to the corresponding amine, the summary (Fig. 1) of available in vivo and in vitro data suggests the likelihood of several intermediates in common with

\footnotetext{
${ }^{4}$ Prekotes (silica gel GF), $250 \mu \mathrm{m}, 20 \times 20 \mathrm{~cm}$ with fluorescent indicator, Applied Science Laboratories, Inc.

${ }^{5}$ Mass spectrometer Model 30, Assoc. Electronics Industry, Manchester, England; Model 104 gasliquid chromatography unit, P. G. PYE Ltd., Cambridge, England; Model PDP 8/m data output system, Dec Digital Equip. Co.; Model 4010-1 visual display unit, Tektronic Corp., Portland, Oregon.
} 
those involved in the metabolism of 1- and 2-naphthylamine. Since 2-naphthylamine is a known bladder carcinogen the implications of a common metabolic pathway with 2nitronaphthalene need to be considered. These studies suggest the need for further evaluation of the nitronaphthalenes and the need for more detailed metabolic studies of related nitro compounds and other chemicals whose metabolic pathways may involve the formation of known or suspected carcinogens.

Moore et al. (1977) have recently referred to an unpublished report indicating that 2nitronaphthalene is metabolized to 2-naphthylamine ( $\beta$-naphthylamine) in the dog; hence evidence of this metabolic pathway in at least two species now exists. In agreement with their recommendation, it is apparent that the nitronaphthalenes and biological samples from animals treated with the nitronaphthalenes should be handled in a manner consistent with the safety precautions and laboratory practice used for handling potentially dangerous compounds. Further, it would seem prudent that laboratory and industrial personnel should minimize their exposure to the nitronaphthalenes in the course of research or manufacturing activities.

\section{ACKNOWLEDGMENTS}

We thank Timothy Riley, Physical Instrumentation Laboratory, Department of Environmental and Industrial Health, School of Public Health, The University of Michigan, for the glc/mass spectral analyses.

\section{REFERENCES}

Bell, S., Troll, W., Teebor, G., and Mukai, F. (1968). The carcinogenic and mutagenic properties of $N$-hydroxy-aminonaphthalenes. Cancer Res. 28, 535-542.

Bonser, G. M., Boyland, E., Busby, E. R., Clayson, D. B., Grover, P. L., and Jull, J. W. (1963). A further study of bladder implantation in the mouse as a means of detecting carcinogenic activity: Use of crushed paraffin wax or steric acid as a vehicle. Brit. J. Cancer 17, 127-136.

Boyland, E., Dukes, C. E., AND Grover, P. L. (1963). Carcinogenicity of 2 naphthylhydroxylamine and 2-naphthylamine. Brit. J. Cancer 17, 79-84.

Brill, E., AND RadomSkI, J. L. (1971). Comparison of the in vitro and in vivo $N$-oxidation of the carcinogenic aromatic amines. Xenobiotica 1, 347-348.

Endo, H., Ono, T., And Sugimura, T. (1971). Chemistry and biological actions of 4 . nitroquinoline 1-oxide. Recent Results in Cancer Res. 34, 1-101.

JoHNSON, D. E., AND CoRNish, H. H. (1976). In vivo nitroreduction of nitronaphthalenes. Toxicol. Appl. Pharmacol. 37, 182 (Abstract).

MitLfR, E. C., AND MiLLER, J. A. (1969). Studies on the mechanism of activation of aromatic amine and amide carcinogens to ultimate carcinogenic electrophilic reactants. Ann. N.Y. Acad. Sci. 163, 731-750.

Moore, R., Woolf, B., Stein, H., Thomas, A., And Finkiea, J. (1977). Letter. Science 195, 344.

ONG, T., AND DESERRES, F. J. (1972). Mutagenicity of chemical carcinogens in Neurospora crassa. Cancer Res. 32, 1890-1893.

Perez, G., and Radomski, J. L. (1965). The mutagenicity of the $N$-hydroxy naphthylamines in relation to their carcinogenicity. Ind. Med. Surg. 34, 714-716.

PoIRIER, L. A., AND WEISBURGer, J. H. (1974). Enzymatic reduction of carcinogenic aromatic nitro compounds by rat and mouse liver fractions. Biochem. Pharmacol. 23, 661-669. 
RADOMSKI, J. L., AND BRILL, E. (1970). Bladder cancer induction by aromatic amines: Role of $N$-hydroxy metabolites. Science 167, 992-993.

Radomski, J. L., Brill, E., Deichmann, W. B., and Glass, E. M. (1971). Carcinogenicity testing of $N$-hydroxy and other oxidation and decomposition products of 1 - and 2naphthylamine. Cancer Res. 31, 1461-1467.

Radomski, J. L., Conzelman, G. M., Rey, A. A., ANd Brill, E. (1973). $N$-oxidation of certain aromatic amines, acetamides and nitro compounds by monkeys and dogs. $J$. Nat. Cancer Inst. 50, 989-995.

Stenhagen, E., Abrahamsson, S., and McLafferty, E. (eds.) (1974). Registry of Mass Spectral Data, Vol. I, p. 331. Wiley-Interscience, New York.

StERnson, L. A. (1975). Detection of arylhydroxylamines as intermediates in the metabolic reduction of nitro compounds. Experientia 31, 268270. 